\title{
CENTENARY OF THE CHEMICAL SOCIETY
}

$\mathrm{T}$ HE Chemical Society is entitled to be congratulated on the whole programme of events arranged in celebration of its centenary during July 15-17. There were receptions and a programme of visits, and three excellent lectures besides the centenary address, all appropriate and all well arranged, and many of them displaying the same leading ideas that marked the opening ceremony and the centenary address. The first official function was indeed the opening of an exhibition illustrating one hundred years of British chemistry at the Science Museum, South Kensington, by the president of the Society, Prof. C. N. Hinshelwood, on July 14. The Minister of Education, who took the chair at the opening ceremony, emphasized not merely the vital place of the learned societies in the cultural and educational life of the community and the landmarks in the progress of chemical science to be seen in the exhibition, but like Prof. C. N. Hinshelwood, the dependence of such achievements upon men of independent, vigorous and original minds in the past.

Prof. J. Read, in his lecture at the Institution of Civil Engineers on "Chemical Personalities a Century Ago" on July 16, took a longer look at some of the founders of modern chemistry, and Prof. E. K. Rideal, lecturing simultaneously at the Royal Institution on "The Work of the Royal Institution in Physical Chemistry in Great Britain", also paid tribute to many honoured names such as Humphry Davy, Faraday, Dewar, Sir William Bragg and Sir Henry Dale. Equally, Sir Robert Robinson, in the Faraday Lecture delivered in the Central Hall, Westminster, on the afternoon of July 16, on "The Development of Electrochemical Theories of the Course of Reactions of Carbon Compounds", linked modern ideas on the electrolytic dissociation of acids and the applications of these principles to the benzene ring and theory of partial valency with the work of Faraday, in whose laboratory at the Royal Institution during Faraday's active experimental life of some forty years, fifteen major investigations were undertaken, all of which had a profound effect on physical chemistry as we know it to-day.

The dominant impression left by Prof. Read's lecture was exactly that of the international unity and fellowship which was such a distinctive feature of the dignified and impressive opening ceremony of the celebrations in the Central Hall the previous day. Prof. Read showed how those chemists who founded the Society formed part of a movement which recognized national frontiers no more than the wandering scholars of the Middle Ages, and which even then was throwing up schools of chemistry which attracted men from all over the civilized world. The birth of the Chemical Society was the outcome of an intellectual ferment as international in character as the gathering which saluted its birth. Prof. Rideal's lecture, on the other hand, illustrated incidentally the reciprocal influence of the Chemical Society on other scientific socioties and institutions. The Chemical Society, as Sir Robert Robinson pointed out, in conveying greetings to the Society from the Royal Society and the other learned societies of Great Britain, had not merely stimulated the formation of other bodies such as the Biochemical Society and the Faraday Society, but had also contributed to the advancement of knowledge in many diverse fields, as was illustrated by that with which the Society of Dyers and Colourists was concerned. The influence, as Prof. Rideal noted in commenting on the fact that five of the professors in the Royal Institution had been presidents of the Chemical Society, was reciprocal, and the Chemical Society owed much to the labours of other societies.

The names in the list of some forty societies and institutions in Great Britain on whose behalf Sir Robert Robinson offered felicitations to the Chemical Society testified to the ramifications of chemical science during the century and to the industries which had been stimulated or transformed by chemical enterprise, and the proceedings on the Tuesday, above all at the opening ceremony and the centenary address, seemed to epitomize the essential spirit of the celebrations. There was colour as well as dignity in the processional entry of the delegates representing overseas Societies, headed by the president, and preceded by the Society's mace-bearer. The president's words of welcome to the representatives of nearly thirty countries were well chosen, touching briefly on the unity of science. Prof. Raymond Delaby, speaking on behalf of these delegates, responded in French. The addresses formally presented by these delegates and by the representatives of British Societies were not read at the meeting but were displayed in the Society's rooms at Burlington House, where they were to be seen at the Royal Society's reception. Mention might be made here, however, of the Swedish glass vase bearing suitable inscriptions and illustrations of chemical equipment which contained the address of the Chemical Society of Stockholm.

If the centenary address of Prof. Hinshelwood on July 15 is given pride of place it is only because it gave fuller expression to the charm of manner and keenness of thought which marked his tenure of the presidential chair throughout the celebrations. If the founders of the Society might have found it beyond their wildest dreams to expect that the head of the Government of the day would honour the Society by his presence at the centenary dinner and that the fellows of the Society and the overseas delegates should enjoy Government hospitality at the luncheon on July 15 and the garden party at Lancaster House on July 17, the explanation is at least in part to be found in the president and those like him who have linked to their scientific attainments such charm and courtesy and organising ability. That much at least can be glimpsed in his centenary address, which will worthily commemorate the celebration long after the memory of the social events and festivities is dim.

Touching briefly on the philosophical questions raised by the celebration of the centenary not of a discovery or of a person, but of a Society, he reviewed in succession the chemical scene at the foundation of the Society and at successive intervals of a generation before, attempting to discern the essential trends to which great events and personalities are related more as occasions than as causes. Here Prof. Hinshelwood challenged thought about some of the central 
issues of our time and formulated our task of preventing an organised society from turning individuals into slaves with all the implications for the relation of the State to science, of industries to the universities, for the organisation of research laboratories and, indeed, for the relation of every scientific worker to the laboratory in which he works and to the science as a whole. Complete individualism means chaos, but it is still the individual who counts; but his problems are different, and at every level in every organisation where men engaged in scientific pursuits those in charge must continue to wrestle with the problems of combining liberty with order to the end of finding that course which is humanly as well as technically the most effective.

Pragmatic as well as suggestive, Prof. Hinshelwood was never doctrinaire, but he did not hesitate to follow his words of appreciation for the increasing number of scientific papers coming from chemical industry, with a warning of the dangers in which military security might involve us or against the restrictions on scientific publication imposed by paper stringency or to plead for adequate facilities for meetings, and in this address he returns in conclusion to the international character of the Society and to the fellowship of those who share the love of chem. istry which was so manifest at the celebrations.

Welcome as may be the generous appreciation of the work of the Society manifest in the addresses of felicitation, the hospitality extended to its fellows and guests at the receptions, visits and social functions, it is to the spirit which pervades the centenary address that we must look chiefly for the firm assurance that the second century on which the Society has entered will be no less noteworthy than that celebrated in July 1947.

\section{ELEVENTH INTERNATIONAL CON- GRESS OF PURE AND APPLIED CHEMISTRY}

$\mathrm{T}$ HE Eleventh International Congress of Pure and Applied Chemistry was held in London during July 17-24, following immediately on the centenary celebrations of the Chemical Society. Some three thousand members and delegates, including many leading personalities in all branches of chemistry, and representing thirty different countries, took part in what must have been the largest international gathering of men of science since the end of the War. A crowded programme had been arranged, consisting of meetings for the reading and discussion of papers, lectures, visits to industrial laboratories and many social events.

More than 1,500 papers were submitted for presentation. For the purpose of reading the papers selected, the Congress met in fourteen sections, representing the various branches of pure and applied chemistry. Several sessions were held jointly between different sections, and the majority of contributions were in the nature of reviews of work already published, or in the process of publication, rather than entirely new material. It is obviously impossible to give more than a very brief indication of the vast amount of ground covered. Only a small fraction of individual contributions can be mentioned, but it will be useful to summarize the main topies of discussion as they provide an excellent indication of contemporary trends in chemistry.

In Section 1 (Inorganic and Geochemistry) the first session was devoted to reactions in solids and $\mathrm{X}$-ray methods, and included a general review by J. A. Hedvall of progress in this field over the last thirty years, and an account by H. L. Riley on the X-ray crystallography of amorphous carbon. At a later session, entitled "Structural Chemistry of Metals and Inorganic Compounds", L. Pauling outlined a new theory of the metallic state. Treatment of interatomic forces in metals by the method of atomic orbitals provides a qualitative explanation of the special properties of the transition metals. Other speakers discussed recent work on the structure of mixed crystals (P. Niggli), molecular compounds (H. M. Powell) and electron-deficient molecules (R. P. Bell). Further sessions dealt with geochemistry and the structure of minerals, and with radiochemistry, and included papers on francium (element 87) (M. Perey), and on protactinium (G. Boussieres and $\mathbf{H}$. Haissinsky). The disappointing fact that any direct reference to subatomic phenomena was excluded. brought to mind the centenary address of the president of the Chemical Society in which he expressed the hope that "the whips of commercial secrecy would not be succeeded by the scorpions of military security" in preventing the publication of research.

In Section 2 (Physical Chemistry) there were symposia on polymers, catalysis and reaction-rates, and spectra. The latter was almost wholly concerned with the absorption spectroscopy of organic compounds. The striking developments in the technique and applications of measurements in the infra-red region were reviewed by J. Lecomte, G. B. B. M. Sutherland and H. W. Thompson. E. Clar discussed the ultra-violet light absorption of aromatic hydro= carbons, and J. M. Robertson the determination of bond-length by X-ray methods. In the session on polymers, held jointly with the Textile and Elastomers Sections, about an equal number of papers were devoted to structural and kinetic aspects. H. W. Melville described the synthesis and properties of a new branch-chain type of polymer built up from cruciform and star-shaped molecules and obtained by condensing together adipic acid, ethylene glycol and a small amount of a polyfunctional alcohol, such as penta-erythritol. Two papers by $\mathrm{H}$. Mark dealt with the mechanism of polymerization reactions and the configuration of polymer molecules. The composition of a binary co-polymer is related to the electronavailability at the radical end of the growing chain and at the double bond of the monomer molecule, and can be predicted from the electronic character of the substituents. J. B. Speakman described the modification of the properties of natural fibres by chemical means, for example, by successively break. ing and re-uniting the cysteine cross-linkages in keratin with reducing and oxidizing agents, and by physical means. Among the topics covered in other sessions were those of mass-spectrometry, magnetochemistry and polarography, and included papers on the measurement of the rate of electrode processest by oscillographic methods (J. Heyrovsky), the thermal and photo-oxidation of olefins (I. Bateman and J. L. Bolland) and the absolute velocity of contact catalysis (G. H. Schwab).

The programme of Section 3 (Organic Chemistry) covered general organic chemistry, heterocyclic compounds, antibiotics, vitamins and growth factors, 